since it not only indicates the advancement of automatic control but also a diminution of the employ. ment of graduates in duties which could be carried out equally well by those with lower qualifications. It is surprising to find that corresponding figures for two of these major branches in the United States differ considerably, being 31 per cent for research and development compared with 23 per cent in Britain, but only 7 per cent for design and construction against 21 per cent, a possible explanation being that development may be carried further in the United States and may include much which is classed as design in Britain. Among the minor occupations, teaching shows a gratifying increase from $3 \cdot 0$ to $5 \cdot 1$ per cent, the present number of teachers being more than 100 , but this is still not enough.

The total number of qualified members of the Institution in 1957 was 2,176 , a figure considerably higher than that given in the Government report on Scientific and Engineering Manpower in 1956. The distribution of these members among thirty-three different industries and occupations is shown and also the number of chemical engineers per 1,000 males employed. As might be expected, the mineraloil refining industry, which may be regarded as the cradle of chemical engineering, heads the list with $7 \cdot 3$ chemical engineers per 1,000 employed, and it may also be noted that it was calculated some years ago that the value of the product per manhour in the oil industry was far higher than in any other heavy manufacturing industry. Oil refining seems to be approaching a state in which the only labour required will be for the erection and maintenance of plant, operation being entirely automatic, and its chemical engineers are employed in research, design, development and management. It would, however, be unwise to conclude from this that the efficiency of an industry is directly related to the number of chemical engineers employed. The iron and steel manufacturing industry, in which many chemical engineering processes are involved, employs only twenty chemical engineers, or 0.05 per 1,000 males, and is at the bottom of the list. It is true that automatic operation has not been adopted in this industry to the same extent as in the case of oil, but this is doubtless because it would be more complicated and difficult to install, and would prob. ably be uneconomic. There is certainly no question of the iron and steel industry being inefficient, but there is a possibility that it does not recognize fully the potentialities of the chemical engineer, and that many of the highly qualified staff who are, in effect, doing chemical engineering work were recruited as metallurgists or mechanical engineers. This example may show the difficulty of interpreting employment statistics.

Of the other items in the list of industries, one is deserving of particular attention, namely, atomic energy. This has already secured the services of more than one hundred chemical engineers, and it seems certain that the number required in the near future will be very large.

All the figures now published will have their real value, in the future. It is to be hoped that a similar set will be published in about five years time, and it may then be possible to make reliable predictions. Even now, it may be regarded as a practical certainty that there will be no overproduction of chemical engineers in the coming quinquennium.

H. E. WATSON

\title{
FUEL AND POWER IN BRITISH INDUSTRY
}

$I^{T}$ $\mathrm{T}$ is abundantly clear that the supply of suitable fuels and the provision of adequate power represent essential factors in any efficient industrial unit. It may well be doubted, however, whether, in view of the ever-increasing complexity of the situation, those responsible for important industrial decisions are always in a position to appreciate thoroughly all the technological and commercial factors involved. It was in the hope of doing something to assist in the planning of such development, so far as the supply of fuel and power is concerned, that the Manchester Joint Research Council arranged a symposium during November 5-7, which was held at the Manchester College of Science and Technology. A very large amount of material has been published on these matters from the technologieal point of view, and it was not the intention of the Council in organizing the symposium to duplicate this, the general theme of the meeting being the interaction between technological advances and their economic consequences.

The meeting was opened by Lord Mills, Minister of Power, who summed up the Government's policy as permitting the consumer to decide from his own experience what is required to meet his own particular needs, coupled with the provision of expert advice, where this is required. It has been estimated that by 1965 the total fuel consumption of the United Kingdom will have risen to about 300 million tons of 'coal-equivalent' 8 year and to 350 million tons by 1975. A marked change in the pattern of the fuel and power used is to be expected; there will prob. ably be a continued switch from the direct use of raw coal to its application in the more refined forms of gas and electricity and an increase in the use of oil, due to the continued expansion of road transport, the re-equipment of the railways, the continuance of recent trends in domestic heating and the change from solid fuel to oil in those industrial and commercial uses where it has special attractions.

This greater refinement means heavy capital investments but offers great savings both in operating and fuel costs, and, in addition, there is a marked reduction in the atmospheric pollution associated with the use of solid fuel.

It is often argued, the Minister said, that the Government should direct the fuel to be used for specific purposes. In reply to this he added: "We should certainly hesitate to adopt such a policy of Government direction on fuel use for two main reasons. In the first place, the detailed policy of control could not really work; there is so much uncertainty regarding the best fuel to employ in particular conditions and, secondly, if there is one thing which central control lacks it is flexibility. A pattern laid down as appropriate at a particular time might quickly become obsolete and uneconomic". It is important, too, in his view, that the importation of oil should be in the crude form, from an increasing variety of sources and processed at refineries in the United Kingdom. 
So far as nuclear power is concerned, there would be a rapid expansion to some 5,000-6,000 megawatts in 1966, and thereafter continued expansion may prove economic. Concerning the use of small coal, this should become progressively a more attractive purchase, and it is the duty of all forms of industry, nationalized or otherwise, to switch their demands so far as possible from larger sizes to small coal.

The remainder of the meeting was devoted to the industrial consideration of oil, coal, gas, electricity and nuclear energy. The lectures on oil were given by Dr. P. H. Frankel, of Petroleum Economics Ltd., who dealt with the economic aspect, and Mr. W. S. Ault and Mr. H. Cunliffe, both of Shell-Mex and B.P. Ltd., who were concerned with the uses. Dr. Frankel, in a most valuable and provocative paper, suggested that with the expansion of existing oil-fields and the opening of new ones-the Sahara was mentioned in particular-there would appear to be abundant reserves on a world scale. Great Britain, however, is especially subject to political vicissitudes, and he therefore stressed the need for a balanced fuel economy. In the past few years vast now oil fields have been found, the exploitation of which, now that they have been located, should be relatively cheap. This oil will tend to press on the existing markets, and he assumed, therefore, that the price of liquid fuel would tend to fall. A question which he posed to the Conference was whether it is more economic for Great Britain to go to the limit of marginal high-cost production of coal with investment on a commensurate scale, or to substitute oil for, say, the last 10 per cent of our requirements. He pointed out that Western Europe is dependent on sea-borne oil, but he believes that there are plenty of tankers available, while pipe-lines based on Marseilles, Rotterdam and Hamburg would facilitate distribution.

Mr. Ault and Mr. Cunliffe's paper on the uses of oil, after stressing its importance in all forms of transport, passed on to consider its use in general industry. Although electrical energy can be produced from coal at the generating station at the lowest cost, there are even here special cases in which oil-firing is worthy of consideration. The efficiency of combined generation of electricity and recovery of waste heat, using either Diesel or gas turbine or both, was given as 80 per cent. The storage space required for oil fuel is much lower than that needed for coal, and oil firing offers further advantages in mechanical equipment, labour costs, convenience and automatic control. Furnaces may be heated by a wide variety of fuels, ranging from propane to heavy fuel oils, and in such processes as steel-making the high radiation from the flame leads to more rapid melting. The question of atmospheric contamination by sulphur was mentioned, though in subsequent discussion it was not clear that, from this point of view, oil is markedly superior to coal. It does, however, possess marked advantages in the absence of grit turned into the air.

In his review of Britain's resources of coal, and considering seams not less than $1 \mathrm{ft}$. thick and not more than 4,000 ft. deep, Mr. A. M. Wandless (National Coal Board) estimated that these are of the order of 1,000 million tons which can be economically worked. He stressed the fact that it is not the mere quantity available but the 'rank', of which the coals proved cover a range unique in Western Europe. With the increase of mechanization the increased costs of production are not likely to go on rising unchecked. This cost of production varies inversely with the rank, of which the various industrial uses extend over a wide range, and low rank does not necessarily imply low quality. The present output of the various types of coal is not seriously out of phase with the resources of Britain, though a slow decline in quality must be expected. About half the output is of low rank, and it is for the technician to ensure that the use of such coal should be as great as possible.

One of the most important contributions was that of Mr. D. Hicks (National Coal Board), on "Coal Utilization". Although the total mineral resources of Britain are limited in type, they are not insignificant in quantity. There is, for example, enough economically accessible coal to sustain a high national productivity for more than a hundred years. It would seem wise to ensure that these natural advantages are not used carelessly, and that we do not become increasingly dependent on external resources, with all the uncertainties and risks, political and economical, that this implies.

From the commencement of the industrial revolution there has been a fairly direct relationship between national income and the consumption of primary fuels, and estimates of the future demands of fuel and power have been based within fairly wide confidence limits on an extrapolation of this relationship. In industry the maximum utilization of time and resources has not yet been achieved, and big improvements in productivity are possible with a smaller expenditure of mechanical energy than extrapolation from past performance would suggest. Mr. Hicks recognized that we cannot sustain a high industrial output in Britain wholly on our internal resources; neither can we support our economy without importing some oil, particularly for our air and road transport systems, for lubrication and for certain chemical feed stocks. He asked, however, whether it is not a matter for serious consideration whether we should become increasingly dependent for heating and for power generation on imported fuel. In pleading for an increased efficiency in the use of fuels of all kinds, Mr. Hicks pointed out that it is too facile to assume that merely by switching from one fuel to another an automatic improvement in efficiency will result. All fuels, both primary and secondary, require close attention to the choice of equipment and to the operation. It is far less costly, ton for ton, and takes far less time to save coal than to create a new pit.

In his lecture on "Gas", Sir Harold Smith (of the Gas Council) emphasized that the industry is passing through a period of change, perhaps the most important in its whole history. It is facing two new challenges, one due to the increasing shortage of suitable fuel and the other from nuclear power, and is meeting these challenges by basic experiments from which a new gas industry may be developed. New types of coal and new materials are being investigated, and in particular the high-pressurehigh-temperature gasification of small, low-quality coal. The collection and distribution of methane from mines and from catalytic plants should make a further useful addition to the supplies available, and he particularly emphasized the interest being taken in the importation of liquid natural gas from America. A thirty-thousand ton tanker would be capable of carrying the equivalent of two million tons of coal. Gas has advantages as an industrial fuel due to its ease of control and the very wide range of temperature which can be obtained. 
In the discussion, Mr. D. P. Welman (North Western Gas Board) envisaged the transformation of the existing industry into a truly chemical one, and mentioned the experiments of the North West Gas Board in the development of the hydrogenation process which, if as successful as appears probable at the moment, may well revolutionize the whole industry. The preliminary work will take some four to five years, and a further three or four years will be required to construct a large-scale plant. $\mathrm{He}$ concluded by claiming that the gas industry uses coal more efficiently than any other major industry does.

"Nuclear Power" was discussed by Mr. P. T. Fletcher (United Kingdom Atomic Energy Authority). Broadly speaking, the capital cost of the present plant is three times that of a conventional coal-fired generating station. The fuel costs, however, are about a half, so that there is not very much to choose for base load operation between the cost of power generated in the two ways. If, however, the bigger and more advanced stations which are envisaged materialize, the cost per unit of electricity generated from nuclear energy may fall as low as $0.4 d$. per unit. A point of great importance in connexion with nuclear power stations is the load factor, which is more important than with coal. So far as the gas-cooled reactor is concerned, the three main lines of development are an increase in the temperature of the gas leaving the reactor, the design of the fuel elements so that heat is transferred to the gas more effectively - thin rods stacked in clusters in uranium oxide were suggested in this connexionand reduction in capital cost by simplification of lay-out. Considerable interest was expressed in the future of the boiling-water reactor using enriched uranium or plutonium as the fuel, a system which, it was suggested, would result in marked reductions in the initial capitel cost. Mr. Fletcher expressed the opinion that it is justifiable to spend $£ 40-£ 50$ million on experimental work when the potential saving might exceed $£ 200$ million. The cost of a prototype plant from the initial laboratory stage is of the order of $£ 20$ million, and he believed, therefore, that two such prototypes may justifiably be designed. In the discussion, Mr. M. Zvegintzov (National Research Development Corporation) stated that about twelve times as much money is being put into research in connexion with atomic energy as into all other fuel projects, and asked what the coal or gas industries could do if they had the £50 million for development purposes which Mr. Fletcher suggested for nuclear power. It is still, in Mr. Fletcher's view, very difficult to predict the next stage of develop. ment, and even the present programme of research and development will take many years to complete. $\mathrm{He}$ was sure, however, that the present United Kingdom pattern of nuclear development was justifiable both economically and technically.

The lectures on "Electricity", by Mr. T. E. Daniel and Mr. A. O. Johnson, were devoted, in the main, to a consideration of its use in electro-heating. It was pointed out that the consumption doubles every ten years, and the view was expressed that the future trend of price should tend increasingly to favour electric energy. The largest single user in Britain is the steel industry, but it was suggested that electrical heating would eventually displace fuel-fired furnaces both for the melting and annealing of glass, and in the ceramic and refractory industries. Advantages of electric heating are its flexibility, the possi- bility of thermal storage, so far as space heating is concerned, and the extent to which, by adequate instrumentation, its utilization could be rendered automatic. In modern conventional power stations an efficiency of 35 per cent can be obtained, and by a marked increase in size 37-38 per cent would not be unreasonable. Both in the lecture and discussion the possibility of extended use of the heat pump was mentioned, which, in the view of Mr. Frank Rostron (Ferranti Ltd.), has great possibilities when it can be built into the structure.

The final session was devoted to a general discussion with particular reference to future trends. $\mathrm{Mr}$. G. A. J. Begg (Imperial Chemical Industries Ltd.) dealt with the chemical industry and gave figures illustrating the marked economies which have been achieved during the past forty years; despite these figures, the curve has not yet become asymptotic and further economies may reasonably be expected. Much depends on the elimination of heat losses by the use of waste-heat boilers and in general the recovery of low-grade heat. The siting of factories in relation to generating stations is an important point, as is the private generation of electricity in industry, the three such main producers being the chemical industry itself, the iron and steel industry and papermaking. In small plants oil has great advantages, but throughout capital cost is a basic factor.

The metallurgical industries were discussed by Dr. T. P. Colclough (British Iron and Steel Federation), who pointed out the astonishing economies in fuel which have been achieved in the past thirty years. In 1927, the consumption amounted to $55 \mathrm{cwt}$. per ton of finished steel ; this had been reduced in 1957 to $28 \cdot 5$. Sintering, the recovery of waste heat, the effective use of blast furnace and coke-oven gas and oil firing have been the major reasons for this. The use of oxygen in the open-hearth furnace to increase the rate of combustion and therefore of refinement is a comparatively new technique, which may well have very marked future influence. In this connexion there is a vast now field in the pneumatic (Bessemer) processes which, with tonnage oxygen available, are opening up a new era.

The trends in general industry were discussed by Dr. W. A. Macfarlane (National Industrial Fuel Efficiency Service), who said that in the past ten years the increase in the energy used in Britain in general industry has been about 40 per cent, and attention was directed to the relatively enormous economies which could be effected by more careful attention to the factors leading to increased efficiency. He believed that 20 per cent of the fuel used could thus be saved.

One may, in conclusion, quote some words of Sir Raymond Streat, spoken at the conclusion of a series of meetings on "Science and Industry", arranged by the Manchester Chamber of Commerce in 1944, to which Mr. Hicks made reference : "If you came to this meeting hoping to have a simple answer served up on a platter, you will be disappointed. You have to wrestle with this matter each for himself. Heavy reading, hard study, anxious thought, persistent inquiry, costly experimentation-these are unavoidable and you will drop behind if you cannot stand the pace. It is going to be a difficult, testing life after the war, but full of interest and reward for those that can take it". It is now more than fourteen years since these words were spoken, but they still apply, and particularly so in respect of the problems of fuel and power.
F. C. ThoMpson 